\title{
LO FANTÁSTICO DE PERCEPCIÓN, LO FANTÁSTICO DE LENGUAJE Y SU EFECTO SUBVERSIVO EN CONTROL TERRESTRE DE JOSÉ GÜICH RODRÍGUEZ
}

\author{
ERWIN SNAUWAERT \\ KU Leuven Campus Brussel \\ erwin.snauwaert@kuleuven.be
}

Recibido: 05-01-2016

Aceptado: 03-10-2016

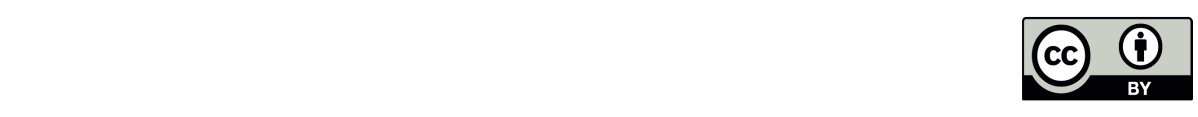

RESUMEN

En la literatura latinoamericana contemporánea tanto los objetos tecno-científicos como los otros elementos temáticos cuya presencia es típica de lo fantástico se vinculan cada vez más a unos experimentos con la enunciación narrativa. Así llegan a convivir un «fantástico de percepción» y un «fantástico de lenguaje», dos modalidades que se elaboran en la colección de cuentos Control Terrestre (2013) del autor peruano José Güich Rodríguez. Concretamente, algunos relatos ponen en marcha la vacilación aprovechando la presencia de una maquinaria futurística, mientras otros se valen de la materialidad del texto, alternando o conectando la elaboración del tema mencionado con unos artificios propiamente estructurales como los juegos con el tiempo de la narración, la metaficción y diversas referencias intertextuales. Finalmente, ambas estrategias actúan de conjunto al constituir un discurso que cuestiona la realidad socioeconómica latinoamericana denunciando la deshumanización y sugiriendo la existencia de unos mundos paralelos.

Palabras clave: Fantástico de percepción, fantástico de lenguaje, objetos tecno-científicos, enunciación narrativa, discurso subversivo.

\section{Abstract}

In contemporary Latin-American literature, techno-scientific objects and other thematic elements whose presence is typical of the fantastic genre are increasingly linked to experiments with narrative enunciation. This way, a coexistence is being installed between a «fantastic of perception» and a «fantastic of language», two modalities which are elaborated in the short stories included in Control Terrestre (2013), written by the 
Peruvian author José Güich Rodríguez. More specifically, some of these short stories set in motion the process of vacillation through the presence of futuristic machines, while others focus more on the material aspect of the text, alternating or connecting the abovementioned issue to properly structural artifices such as playing with narrative time, metafiction and various intertextual references. Finally, both strategies give birth to a discourse that questions Latin-American socio-economic reality by denouncing an dehumanizing world and suggesting the existence of parallel universes.

KEY WoRDs: Fantastic of perception, fantastic of language, techno-scientific objects, narrative enunciation, subversive discourse.

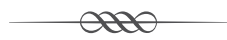

\section{INTRODUCCIÓN}

Aunque por lo general suele ser difícil encontrarles un denominador común a los diferentes textos que componen un libro de cuentos, este problema no se plantea en Control Terrestre (2013), del autor peruano José Güich Rodríguez (Lima, 1963), cuyos ocho relatos ponen en marcha un proceso complementario para establecer el efecto fantástico. Según la famosa definición de Tzvetan Todorov, este efecto fantástico es inducido por la vacilación entre «lo extraño» («l'étrange») y «lo maravilloso» («le merveilleux»), dos términos extremos con los que personajes y lectores califican unos acontecimientos ajenos a su experiencia de lo real respectivamente de pura ilusión o de indicio de lo sobrenatural (1970: 29). Más específicamente, esta vacilación se realiza mediante una transgresión en los niveles semántico, sintáctico o discursivo del texto. En el primer nivel caben unos procedimientos retóricos propios del enunciado, como la exageración, la confusión entre significación literal y figurada o la presencia del bestiario y de objetos descomunales, mientras el segundo examina cómo el relato ordena los eventos para poner en evidencia su carácter insólito. Finalmente, el nivel discursivo, afecta a la enunciación, centrándose en unos juegos con el tiempo y el espacio, en la metalepsis o en otros artificios narrativos que transmiten la sensación de duda propia del género fantástico (Todorov, 1970: 81-87).

Para Mery Erdal Jordan, esta problemática discursiva, por su relación directa con el lenguaje, es la que mejor permite acercarse a lo fantástico en la época postmoderna. Al abandonar el ideal de la representación típica del rea- 
lismo y, hasta cierta altura, también del modernismo, el postmodernismo acabó minando los fundamentos de lo fantástico que, para establecer la inquietud y la duda, exactamente precisa de un ambiente verosímil (1998: 53). Sacrificando su naturaleza referencial y dándose como juego autosuficiente, el texto postmoderno borra los límites de lo fantástico y obliga al género a inventarse de nuevo por medio de unos experimentos con la enunciación (1998: 38). Según David Roas, lo fantástico aprovecha a este respecto unos artilugios narrativos que se articulan de manera difusa, por lo que «[e]n el momento de enfrentarse a la representación de lo imposible [la] expresión [de los narradores] se vuelve oscura, torpe, indirecta» (2011: 264). Con el objetivo de «significar un indesignable» y de instaurar una «retórica de lo indecible», los narradores se valen de unas «estrategias discursivas» como las metáforas, los neologismos, el oxímoron o los adjetivos connotados y explotan sistemáticamente la narración autorreferencial mediante la intertextualidad o unos «juegos de metaficción (...) que ponen en crisis la ilusión de realidad que postula la mimesis» (Roas, 2011: 266).

Por lo tanto, Tahiche Rodríguez Hernández hace una «distinción entre un fantástico de percepción y un fantástico de lenguaje o de discurso» (2010: 4). La primera modalidad «aparece vinculada a una concepción del lenguaje caracterizada por la confianza en sus propiedades icónicas y sus capacidades representacionales» (2010: 4) y genera la vacilación por la mera integración de «una figura» sobrenatural («el vampiro», «el objeto maldito», «el doble»...) en un contexto por lo demás mimético (2010: 3-4). En la segunda, en cambio, «esos límites epistemológicos han sido reelaborados, posibilitando que la figura tienda a perder su carácter fenoménico y su dimensión visual» (2010: 4), o sea, la hesitación sobre todo procede de una disposición específica de los recursos narrativos (2010: 5).

Precisamente, estas dos modalidades de lo fantástico se perfilan de manera ejemplar en Control Terrestre de Güich Rodríguez, que es considerado por Elton Honores como uno de los autores fantásticos peruanos más significativos de los años 1980-2010 (2011: 32). ${ }^{1}$ Concretamente, lo fantástico de percepción se realiza en los relatos «Control Terrestre», «El Sembrador», «El visitante», «La nave olvidada», «No mirar por las ventanas» $\mathrm{y}$ «El archivo de N». Estos dos

1. A este respecto, Honores cita «La reina madre», un cuento incluido en Los espectros nacionales (2008), que establece un ambiente apocalíptico y monstruoso alrededor de la protagonista, una mujer vieja que está obligada a abandonar su vivienda a causa de los proyectos de una potente empresa constructora. Una bandada de pájaros defiende a la anciana, defecando incansablemente sobre los edificios modernos hasta volverlos inutilizables y se preparan para atacar a la civilización misma (2012a: 463). 
últimos cuentos participan también de lo fantástico de lenguaje junto con «Nocturno de Viena» y «La Boca del Payaso». Por fin, veremos cómo la concomitancia de estas dos variantes de lo fantástico es significativa al cuestionar ciertos aspectos de la realidad socioeconómica latinoamericana contemporánea.

\section{LO FANTÁSTICO DE PERCEPCIÓN: LOS OBJETOS TECNO-CIENTÍFICOS}

Si tomamos en cuenta los temas que, en la óptica de Rodríguez Hernández y de Honores, son típicos de lo fantástico de percepción, constatamos que la primera serie de relatos deja desatendidos casi completamente «la presencia del bestiario», «el uso de símbolos y alegorías» y «la figura del doble» (Honores, 2010: 166) para fijarse sobre todo en «los objetos fantásticos» y «la presencia de las máquinas como signo de la modernidad» (2010: 190-191). ${ }^{2} \mathrm{Si}$ bien tales atributos altamente tecnológicos y hasta futurísticos pueden aparecer accidentalmente en otros relatos — como la cámara «infalible» en «El Sembrador» (Güich Rodríguez, 2013: 43) o el cinturón con el que se hace humo el misterioso Coppelius en «El Visitante»—, ${ }^{3}$ se elaboran de forma más manifiesta en «Control Terrestre», el cuento que abre el libro homónimo, «La nave olvidada», «No mirar por las ventanas» $\mathrm{y}$ «El archivo de N».

A primera vista, el cuento inicial tiene más de ciencia ficción, género que «can easily be distinguished from the fantastic, in that the fictitious world is an extrapolation of our own, and its norms of logic are based on existing scientific discoveries and theories» (Chanady, 1985: 5), que de literatura fantástica. Sin embargo, también se concreta en él la «antinomia» (1985: 12) típica de lo fantástico que consiste en la presencia simultánea y conflictiva de lo real y de lo sobrenatural. Aparece una Lima atormentada por el «cambio climático global» (2013: 15) y plagada de pobres que «vivían en [un] mundo asfixiante y sin muchos horizontes» (Güich Rodríguez, 2013: 20). Este panorama apocalíptico no difiere mucho del triste espectáculo que suele ofrecer la ciudad hoy día, si no fuera porque es suministrado por unos héroes, el «experto operativo» (2013: 14) Velaochaga y su piloto Selene, que la supervisan desde una

2. Cabe señalar que Honores (2012b) también reemplaza la noción de 'narrativa fantástica' por las de 'narrativa imposible' o 'narrativa del caos', que incluyen manifestaciones como la ciencia ficción, el horror o el terror. A este respecto, Honores presenta el aspecto 'imposible' como rasgo distintivo del género, para arreglar cuentas con un realismo, sobre todo de orden social, que se considera a sí mismo como superior y suele marginar a la narrativa del caos. Claro está que estas consideraciones no afectan a la importancia de la escritura mimética que sirve para poner en marcha el imprescindible proceso de vacilación.

3. Para evitar repeticiones, postergamos el análisis más detallado de estos cuentos a la tercera parte, en la que también quedará clara su influencia en el carácter subversivo del texto. 
cápsula espacial. La perspectiva futurística se comprueba en el artículo de prensa que abre el texto: va fechado de 2061, año en el que desde hace tiempo «inauguraron [una] Base en el Mar de la Tranquilidad» (Güich Rodríguez, 2013: 13, 22) y se disputan partidos de fútbol entre androides (2013: 18). El objetivo de esos controles es ver cómo uno de los distritos limeños, víctima de unas filtraciones de agua causadas por unas lluvias torrenciales, puede ser rehabilitado y transformado en «un parque temático» que permita «saber cómo vivía la gente hace cien años» (2013: 17).

Precisamente la coexistencia de una imagen futurística de la ciudad, repartida de manera muy abstracta en unos sectores A, B, C y D (2013: 24), y otra, más habitual, pone en marcha la vacilación: el sondeo de la ciudad efectuado con toda suerte de cacharros sofisticados — «anteojos telemáticos», «computadora-visor», «simulador portátil» (2013: 18, 19, 24) — atina a captar «el incesante discurrir de (...) velocísimos destellos (...) en un movimiento continuo que dibujaba el contorno del inmueble a tal grado de perfección que creaba una copia casi exacta de un objeto desaparecido» (2013: 30). El que este objeto que concentra en sí «unos flujos de energía» (2013: 35) necesarios para «los primeros habitantes, ávidos de agua en un mundo por hacerse» (2013: 36) no sea otro que «uno de los viejos depósitos para almacenamiento de agua» (2013: 24) muestra hasta qué punto lo sobrenatural se compenetra con el mundo existente. Como también lo señala Martín-Barbero, tales imágenes supuestamente futurísticas y presentadas como si fueran registradas por una «cámara colocada en el helicóptero» y procesadas por una avanzada «digitalización» son ideales para describir las «cibernéticas metrópolis actuales (...) desde las cartografías catastrales construidas desde arriba, y a las que nada escapa» (2002: 13). Asimilando la amenaza del futuro a la experiencia cotidiana, este entorno despersonalizado nutre en el lector el sentimiento de inquietud y fortalece el aspecto fantástico del cuento.

En el segundo relato, el Doctor Roberto E. Díaz, un científico de origen hispano, le narra a su compañero estadounidense Floyd cómo su amigo Enrique, cuando era un chaval de doce años, se embarcó en una vieja «nave, semejante a un avión en pequeña escala, pero de unas líneas particulares». «Pese a que no se veían ni turbinas ni hélices por ningún lado» (Güich Rodríguez, 2013: 117-118), el extraño aparato lanzó a Enrique al espacio para devolverlo a su casa limeña años después pero con una edad incambiada. Al llegar, el chico se dispone a llevarse inmediatamente en un «viaje de retorno» al propio Díaz que le espera pertrechado de un «pequeño maletín dispuesto para la ocasión» (2013: 126) y, por lo tanto, parece estar familiarizado con el misterio- 
so destino. La posible pertenencia de Díaz a otro universo nuevamente causa un asombro que es intensificado por el escepticismo de Floyd, su interlocutor, que no se fía de él y siempre le pide que acorte su historia.

Una misma atmósfera se instaura en «No mirar por las ventanas» cuando el protagonista, que se mudó de Lima a Barcelona para convertirse en novelista de ciencia ficción, ve desde su ventana cómo unos tipos de parecer futurístico «enfundados en trajes de color naranja (...) en el estilo de las películas sobre catástrofes radioactivas o epidemias» descargan de un contenedor «unos depósitos cilíndricos con siglas que no reconocía» (2013: 103). Lo extraño es que solo aparezcan estos hombres cuando el protagonista mira por la ventana junto a la cual está intentando lanzar su carrera literaria: no los ve nadie más que él y no los encuentra cuando baja a la calle para observarlos desde más cerca.

Finalmente, otra muestra significativa de «la presencia de la tecnología y la ciencia en la vida cotidiana» (Honores, 2010: 190) se rastrea en «El archivo de $N »$, relato en el que Teruel, el narrador-protagonista, encuentra en la entrada de su casa un manuscrito atribuido a Ricardo Palma, un eminente representante de lo fantástico peruano ${ }^{4}$. En esas páginas Teruel lee cómo Palma, cuando era soldado en la guerra entre la Alianza Pacífica y España, atisba «algo fuera de lo común en las aguas frente al Callao (...) una figura de contornos extraños (...) de grandes dimensiones» (Güich Rodríguez, 2013: 133) y decide acercarse en lancha a la misteriosa silueta.

Al cabo de media hora, se descubren luces debajo del agua, ante el terror de los grumetes (...) producto de una agitación de las aguas cuando «eso» emerge. Palma alcanza a ver muy de cerca el objeto: es metálico, fabricado con láminas cuyas junturas bien podrían recordar las escamas de un pez. El desplazamiento de masa que produce es de tal envergadura, que el bote parece una caja de fósforos (...) Palma cae al agua (...) Los grumetes, aterrados, ven cómo se abre una escotilla sobre el lomo del «monstruo», salen dos hombres vestidos con trajes de marineros e introducen al náufrago en el vientre de la bestia (Güich Rodríguez, 2013: 135-136).

El enigma es intensificado por la descripción imprecisa del extraño artefacto («eso», «objeto»), por el miedo que inspira («terror», «aterrados», «mons-

4. En efecto, varios escritos de Ricardo Palma (1833-1919), como los que están recogidos en Tradiciones - una serie de textos publicados entre 1872 y 1889, que también se cita en el propio cuento (Güich Rodríguez, 2013: 132)—, son de orientación fantástica. A esto se añade que su hijo, Clemente Palma (18721946), le siguió las huellas, publicando obras de ciencia ficción, como, por ejemplo, la novela XYZ (1935). 
truo», «bestia ») así como por el hecho de que el propio Palma es atrapado en él. Desde las bodegas, este lo describe como una «máquina submarina, con una maniobrabilidad asombrosa» cuya tripulación «elude olímpicamente cualquier explicación sobre la naturaleza del navío y la tecnología que lo impulsa» (2013: 140). Sin embargo, Palma insiste al mismo tiempo en el carácter ambiguo de la experiencia señalando que "para quien lo vive, como él, es algo tan natural como respirar» (2013: 139), lo que otra vez da tierra a una confusión entre lo real y lo sobrenatural y hace que, como se verá en la tercera parte, «la presencia de estas máquinas (...) provoque una nueva subjetividad, una mirada distinta sobre el mundo» (Honores, 2010: 191). ${ }^{5}$

\section{LO FANTÁSTICO DE LENGUAJE: METAFICCIÓN, INTERTEXTUALIDAD}

Y ESTRATEGIAS TEMPORALES

Estos dos últimos cuentos ponen en marcha la vacilación no solo gracias a la incertidumbre ontológica inducida por los objetos tecno-científicos sino también porque se aprovechan de la propia narración a través de la metatextualidad y la intertextualidad. Además, «La Boca del Payaso» acopla tales relaciones intertextuales a otro aspecto de la estructura narrativa elaborando una estrategia temporal retardataria. El juego con el concepto de literatura en general y de literatura fantástica en particular que se establece en «No mirar por las ventanas» ya se anuncia desde el principio del cuento, donde se cita 2001 Odisea del espacio, la novela de Arthur C. Clarke que también le sirvió de guion a la famosa película de Stanley Kubrick. Estas referencias alimentan la ya citada ambición literaria del héroe y son reforzadas por los misteriosos hombres vestidos de naranja cuyo recuerdo obsesivo lo incitan a escribir una obra que exactamente comienza por las palabras «Unos hombres de traje anaranjado interrumpieron su jornada de escritor a tiempo completo...» (Güich Rodríguez, 2013: 106). Refiriéndose a sí mismo, el relato participa de la metaficción, o sea, de «la narrativa en la que son puestas en evidencia las convenciones que hacen posibles la existencia misma de la narrativa, en otras palabras, (...) toda narración cuyo objeto (...) es la narrativa» (Zavala, 1998: 11).

Es llamativo que esta autorreferencia no solo incida en la actividad de

5. Concretamente, este cuento conectará con la deslegitimación de la verdad única. Por el resto, se inspira en la biografía de Ricardo Palma: el escritor realmente tomó parte como efectivo de la Armada peruana en la batalla de El Callao en la que consiguió salvarse por milagro. También estuvo preso en un barco en El Callao, por haberse resistido como director de la Biblioteca Nacional al gobierno chileno. Aunque el secuestro a bordo del submarino es puramente ficticio, estos paralelismos con la vida real de Palma refuerzan el efecto fantástico. 
escribir —después de haber visto a los operarios de naranja, el héroe logra producir en un tiempo récord un manuscrito que se disputan varias editoriales - sino también en el género fantástico como tal. Basando su trabajo en su «experiencia (...) insólita» (Güich Rodríguez, 2013: 106) con los obreros, el protagonista califica su texto de «híbrido posmoderno con toques de novela de misterio, ciencia ficción (...) con un final sorprendente, inesperado» (2013: 107). Visto que generalmente «los recursos de la metaficción y la intertextualidad determinan el nivel narrativo que dialoga con otros textos literarios» (Macedo Rodríguez, 2010: 62), el cuento así se pone como piedra de toque a la literatura fantástica en particular. ${ }^{6}$

Además, el aspecto fantástico de la autorreferencia se corrobora en su relación con la metalepsis, una figura que trastoca la lógica narrativa, mezclando impropiamente los niveles del narrador y de los personajes. ${ }^{7}$ Animado por las «elogiosas críticas» consagradas a su obra que «estaba en primer lugar en las ventas», el héroe acaricia el proyecto de adaptarla al cine y aborda nada menos que una «gira de presentaciones por Hispanoamérica» y España, que debería asegurarle un puesto en los cánones de lo fantástico (Güich Rodríguez, 2013: 108). Cuando en este tour de promoción vuelve a pensar en los seres estrafalarios cuyas «maniobras incomprensibles» le «sirvieron de impulso», como por encanto se topa de nuevo con ellos (2013: 109). En ese mismo momento, los obreros de naranja demuestran hasta qué punto la fama artística puede ser contraproducente: cuando el héroe llega hasta ellos con la intención de «invitarlos (...) y obsequiarles libros autografiados» (2013: 110), los operarios lo inmovilizan y lo cargan a uno de sus contenedores:

uno de ellos extrajo un aparato, con el cual lo escaneó diferentes veces (...): tres de los sujetos trajeron un cilindro; alguien le colocó un brazalete, cuya descarga

6. Macedo Rodríguez señala en su estudio de La ciudad ausente de Ricardo Piglia que el diálogo establecido por la metaficción y la intertextualidad no solo afecta a lo estético, integrando así lo fantástico, sino también a lo político (2010: 62). Esta última dimensión también se elaborará en la tercera parte de este trabajo.

7. Como la define Gérard Genette, la metalepsis es en un cambio de un nivel narrativo a otro que no pasa por la narración (1972: 243). Se produce, por ejemplo, cuando el narrador no le delega la palabra a un personaje sino que se pone 'físicamente' a su lado. Este es el caso de los hombres de naranja que, a pesar de ser el objeto del relato, se atacan al héroe-narrador que cuenta su historia. Franqueando la frontera entre dos universos que normalmente están nítidamente separados, la metalepsis fortalece el efecto fantástico. Así, este texto de Güich recuerda, en el contexto de la literatura latinoamericana, el famoso ejemplo del cuento «Continuidad de los parques» —incorporado en la segunda edición de Final del juego (1964) de Julio Cortázar, otro representante emblemático del género fantástico- en el que un personaje termina apuñalando al «narrataire» (Genette, 1972: 227), el destinatario del relato con el que puede identificarse el lector. 
lo atontó. En medio del sopor, percibió que lo alzaban en vilo, lo introducían al cilindro, lo sellaban (...). Y luego, la terrible sensación de que lo trasladaban al container y apenas el tiempo mínimo (...) para sentenciar que es poco aconsejable (...) pensar en gente vestida de naranja y mucho menos escribir novelas que lleven por título No mirar por las ventanas (Güich Rodríguez, 2013: 110).

Cerrándose sobre sí misma, la narración enseña que el efecto fantástico no depende tanto de las actividades casi automatizadas de «los sujetos de los trajes espaciales» (2013: 104) sino del hecho de que defraudan la pertinencia de la escritura. Por estas vías, la metaficción cuestiona los límites de la literatura y lleva a una interpretación fantástica del texto.

En el otro cuento citado ya en la elaboración de lo fantástico de percepción, «El archivo de N», lo fantástico de lenguaje se manifiesta a través de la intertextualidad que, como lo afirma también Elton Honores, es otro de los procedimientos que contribuyen a la «renovación formal» (2010: 36) que se lleva a cabo en la narrativa fantástica contemporánea (2010: 195). La importancia de la intertextualidad ya se desprende de la aficiones del protagonista, el editor Teruel, que está fascinado por las películas policíacas de John Houston o Howard Hawks y por Puccini, cuya ópera La Bohème podría aludir al acontecimiento más importante del relato, el vagabundeo del submarino Nautilus (2013: 127). Estas alusiones constituyen el trasfondo cultural contra el cual aparecen las referencias a Ricardo Palma y a Julio Verne. La relación entre la intertextualidad y lo fantástico ya se desprende de la hesitación que experimenta Teruel al estudiar el manuscrito abandonado: le cuesta atribuírselo a Palma porque no tiene su «tono socarrón» típico y "podría publicarse en el suplemento del domingo como un relato» (2013: 145). La trivialidad del texto condiciona la vacilación, valorando el efecto de lo real en el contexto inusitado del submarino, y su temática deja entrever «las coincidencias con una clásica novela» (2013: 136), que resulta ser Veinte mil leguas de viaje submarino, de Julio Verne (2013: 140). Luego, el protagonista detalla la filiación entre la novela del escritor francés y el texto de Palma en un expediente «archivo de N» (2013: 144), cuyo nombre remite a las iniciales de Nemo, el personaje de Verne, o de su barco, el Nautilus, y coincide con el título del cuento.

Además, la afinidad con el texto francés es reforzada por una metalepsis: la barrera entre narrador y personaje se franquea cuando Teruel se topa con el propio Nemo, quien trata de convencerlo de la veracidad del documento. Cuando Teruel alega que por aquellos tiempos tan impresionantes submarinos ni siquiera existían, Nemo le enseña una notable coincidencia temporal: 
visto que Verne abordó su proyecto novelístico en 1865, la extraña nave bien podría haber ayudado a la Alianza Pacífica en su combate contra los españoles en 1866 (2013: 153, 154). Nemo también le asegura que mucho más tarde fue a disculparse ante Palma por haberle detenido en el barco, ocasión en la que este le regaló el manuscrito. Esta metalepsis lleva así, a una «confluencia de dos (o más) tiempos en un mismo instante» y «produce la imposible comunicación (...) entre dos órdenes de la realidad» (Roas, 2012: 110) digna de lo fantástico.

Que el submarino se sustraiga al tiempo convencional se ilustra en el hecho de que Teruel, apostado en el malecón de Chorrillos, observa cómo se despide Nemo antes de bajar «a las profundidades de su navío» (Güich Rodríguez, 2013: 157) y emprender otro viaje más allá de los límites del tiempo. Contemplando al «capitán de un submarino que existe en la ficción y en la realidad» (2013: 155), Teruel se da cuenta de cómo se invierte la jerarquía entre ambos universos. Siendo testigo de algo descomunal que «parece ser premonición del fin de una era», el héroe confiesa ya no estar «obnubilado por la razón» (2013: 152) y quiere dedicarse plenamente a su pasión por las «historias extrañas» (2013: 144, 157). Por estos indicios intertextuales, lo fantástico se convierte en un prisma por el que se tamiza la realidad: publicando finalmente el texto de Palma (2013: 155), Teruel dará crédito a la coexistencia de lo real y de lo insólito y se declara dispuesto a considerar la historia desde la ficción.

Finalmente, en «La Boca del Payaso» la intertextualidad está presente de forma mucho más implícita. ${ }^{8}$ En este relato, un directivo quiere disfrutar con su esposa y su hijo, apodado «el diablillo», de una estadía en un parque recreativo llamado «La Boca del Payaso» (Güich Rodríguez, 2013: 65-66), pero, al enfrentarse allí con una sesión de team-building de una empresa, decide exterminar a todos los participantes. Aunque el parentesco nunca se señala explícitamente, el espacio donde tiene lugar la matanza recuerda «Con Jimmy en Paracas», conocido cuento de Huerto Cerrado (1968), de Alfredo Bryce Echenique. Si bien el relato de este otro autor peruano no sitúa la acción en Chosica sino en Paracas, describe un ambiente vacacional parecido e insiste en los mismos detalles. Como lo indica Snauwaert (2016: 152-154), en ambos casos se presta una atención detenida a las formalidades en recepción, la piscina arroba a los dos jóvenes protagonistas y las estancias se realizan en contextos com-

8. Las únicas referencias explícitas se encuentran en el epígrafe en el que se reproducen los versos iniciales de «Sympathy for the Devil» de los Rolling Stones (Güich Rodríguez, 2013: 65) y en el nombre de Lovecraft (2013: 71), el escritor de relatos de horror, que delatan el aspecto diabólico escondido en el cuento. 
parables: en «Con Jimmy en Paracas», Manolo acompaña a su padre que debe venderles tractores a unos campesinos adinerados, y el ejecutivo del cuento de Güich se molesta por la rutina empresarial de otra compañía agrícola. Sin embargo, el aspecto intertextual más llamativo es la insistencia en la palabra inglesa «bungalow» (2013: 66), puesta en evidencia por las comillas en Bryce y por las itálicas en Güich. En «Con Jimmy en Paracas», este vocablo prolifera en el texto y hasta lo termina: tras una dura jornada de trabajo y de humillaciones, el padre le pregunta a Manolo «qué quiere decir "bungalow" en castellano» (Bryce Echenique, 1981: 31), desconocimiento del inglés que revela su baja condición social. Esta mediocridad contrasta con el lujo que se gasta el guapo Jimmy, el hijo de uno de sus jefes, que intenta corromper a Manolo estimulándolo a tomar sus primeros whiskies, invitándolo a fumar y haciéndole avances homosexuales. ${ }^{9}$ Por eso, Jimmy se convierte en un «ángel del mal» (Bensoussan, 1985: 48) que explota a las clases sociales inferiores y Paracas, que a primera vista era un tipo de paraíso lleno de "palmeras, flores» (Bryce Echenique, 1981: 24), se transforma en un infierno.

De esta forma, el paralelismo implícito con el texto bastante realista de Bryce Echenique intensifica la vacilación y favorece la lectura fantástica de «La Boca del Payaso». Este efecto también se desprende de la estrategia temporal retardataria, por la que se postergan los designios demoniacos de la familia modelo y la interpretación literal de las palabras «el diablillo de mi hijo» (Güich Rodríguez, 2013: 65). Solo al final el lector se entera de que la obsesión del niño por «permanecer minutos interminables» (Güich Rodríguez, 2013: 66) en el fondo de la pileta y «los juegos de su tablet (...) sangrientos y sádicos» (2013: 67) no son exageraciones proferidas por el padre sino manifestaciones efectivas de su naturaleza sobrehumana y de sus capacidades maléficas. ${ }^{10}$ Igualmente, el narrador-protagonista deja que la matanza se revele muy indirectamente a través de los medios de comunicación y solo hace unas conjeturas al respecto utilizando el condicional: «Al regresar a nuestro aposento, encendería el televisor y oiríamos los primeros reportes que informaban a la opinión pública sobre la misteriosa masacre ocurrida esa tarde en un centro recreacional de Chosica» (2013: 70). Callando a más no poder el desenlace catastrófico se opera una «dilatación fantástica del tiempo» que es típica en el

9. A este respecto, Bensoussan asocia «bungalow» a la homosexualidad de Jimmy por su semejanza con la palabra «buga», que en algunas regiones latinoamericanas, remite a «bujarrón», o sea, a «homosexual», como se da el caso en Tres Tristes Tigres de Guillermo Cabrera Infante (1985: 49).

10. Para Todorov, tal hesitación entre una acepción literal y figurada también es una de las características de la literatura fantástica (1970: 83-84). 
género (Roas, 2012: 108). Tomando en cuenta todos estos elementos, hasta se podría decir que el funcionamiento intertextual desemboca en un procedimiento de «reescritura» (Gignoux, 2006: 5): «La Boca del Payaso» no hace otra cosa que adaptar «Con Jimmy en Paracas» a las leyes de lo fantástico.

Junto al juego con el tiempo, que también se vislumbra en «Nocturno de Viena», ${ }^{11}$ la referencia implícita al cuento de Bryce fortalece el proceso de vacilación y muestra cómo la tonalidad realista necesaria a la aparición de lo fantástico se plasma tanto a partir de la organización temporal de la narración como de su composición intertextual, conforme a lo que avanza Bianco Amaral: «as partes da constitução narrativa (discurso direto, voz, personagens, intrusão, etc.) não são, necesariamente, os únicos aspectos que provacariam realismo na obra, mas o que criaria o tom de real seria o fato de o texto ser composto intertextualmente como conjuntura da produção, e assim (re)tomar as vozes existentes no mundo» (2012: 58). Concretamente, el parentesco con el texto de Bryce Echenique induce una lectura referencial y provoca por lo tanto una sensación de cotidianidad. Esta sensación también está implicada en el concepto freudiano de «inquietante extrañeza» ${ }^{12} \mathrm{y}$, para David Roas, constituye «un recurso fundamental para (...) convencer al lector de "la verdad" del fenómeno imposible» y asegura «la coexistencia de lo posible y lo imposible» propia de la literatura fantástica (2011: 263).

\section{UNA LECTURA SUbVERSIVA DE LO FANTÁSTICO}

A pesar de que instalan la hesitación por dos vías distintas, lo fantástico de percepción y lo fantástico de lenguaje se compenetran al inducir una lectura ideológica de los relatos comentados y corroboran así la afirmación de Honores de que «los textos fantásticos también tienen un componente político» (2010: 207). Concretamente, estas dos modalidades contribuyen a revelar la fuerza subversiva que se esconde en la «actitud desmitificadora» del sujeto fantástico. Alejándose de la lógica común y encarnando una visión incon-

11. Como se verá en la tercera parte, en «Nocturno de Viena», este juego se concretará sobre todo en el establecimiento de un nivel temporal proléptico paralelo al tiempo de la narración.

12. Esta «inquietante extrañeza» coincide con el concepto de Unheimliche que fue formulado por Freud en su ensayo del mismo nombre (1919) y que consiste en una sensación de angustia causada por la ruptura de la racionalidad tranquilizadora de la vida cotidiana. Para dar cuenta de su relevancia literaria, conviene mencionar a título de ejemplo que Rubio, en su tentativa de situar la obra vanguardista de los escritores uruguayo y chileno Felisberto Hernández y Juan Emar ante lo fantástico, se vale de la «inquietante extrañeza», señalando que esta sensación puede ser inducida tanto por ciertas vivencias (la reanimación de unas complejos infantiles o de unas creencias arraigadas) como por la literatura y que, en este último caso, depende imperativamente de la presentación del fenómeno descomunal dentro de una realidad familiar y cotidiana (2012: 94-95). 
gruente, este «supone un proceso de deslegitimación de la verdad única» (2010: 208) y se hace el portavoz de una «crítica de la modernización» (2010: 211).

\subsection{La crítica de la modernización: la deshumanización}

El hecho de que «La Boca del Payaso» termine con el triunfo del narrador que, por la hecatombe que causa, será puesto «como ejemplo de un ejecutivo que no descansa ni siquiera en sus vacaciones» por «el mandamás absoluto de Hades Incorporated» (Güich Rodríguez, 2013: 71) no solo invita a una lectura irónica del título — se establece un reino luciferino en un lindo paisaje campestre dominado por «una colina (...) que se asemejaba a uno de esos hombres de rostro elástico y colorado que hace reír a tantos humanos» (2013: 66) - sino que parodia ciertas costumbres vigentes en el mundo de negocios moderno. Vengándose del "pésimo gusto» de las «olimpiadas recreativas anuales» (2013: 69) de la productora de espárragos e incitando con una retórica vacía a sus propios compañeros a «emprender nuevos retos», «incorporarse a nuestros objetivos» $\mathrm{y}$ «sacar dividendos en vez de permanecer en el interior de las montañas» (2013: 70), se burla de un léxico empresarial rimbombante así como del arribismo y de la despiadada competencia comercial que en la sociedad contemporánea hacen caso omiso de los intereses humanos.

Esta deshumanización también es inherente a lo fantástico de percepción, en la que la maquinaria sofisticada no resulta ser nada gratuita. Para Brown, encarna una simbiosis entre «la tecnología y el discurso de la modernidad» y «es el vínculo que vemos establecerse no sólo en los estudios literarios que examinan el tratamiento temático de la tecnología, sino en los estudios culturales que intentan entender el impacto de nuevas tecnologías en la formulación de la cultura latinoamericana» (2007: 736). De esta manera, esta tendencia incluye una dimensión posmoderna y le incita a la escritura fantástica a vincular lo cotidiano a unas nuevas formas de expresión. Este valor ampliamente cultural también es explicitado por Kurlat Ares, quien alega que «la ciencia ficción es un modo de leer la cultura (mucho más que forjar un futuro ilusorio)» (2012: 18), y se perfila muy claramente en el cuento titular. ${ }^{13}$

13. Estas ideas retoman la posición que formuló McHale al tratar el tema en el contexto más global de la literatura postmodernista:. "In general (...) postmodernist writers are more interested in the social and institutional consequences of technological innovation, the social arrangements these advances give rise to, rather than in the innovations themselves» (1987: 66). 
Esbozando un panorama «distópico» de Lima, «Control Terrestre» se aproxima a la ciencia ficción que, por lo demás, en muchos países de América Latina aborda «temáticas vinculadas con distintos aspectos de (...) lo sociológico, lo político, lo filosófico (...) y lo psicológico» (Kurlat Ares, 2012: 15). ${ }^{14}$ Más que proponer una visión del futuro, el cuento denuncia la deshumanización y el deterioro actuales de la capital peruana donde «el caos y la pauperización reinaban sin límites» (Güich Rodríguez, 2013: 20) y confirma las observaciones que hace Musset acerca de las películas de ciencia ficción: «la ciudad del futuro (...) parece diseñada solo para reflejar el lado oscuro de las megalópolis contemporáneas que padecen problemas y defunciones presentados como insuperables: congestión, contaminación, (...) disparidades sociales, violencia permanente» (2007: 66). A estas alturas, Musset también llama la atención en el estrecho vínculo entre ciencia ficción y la propia América latina, alegando que este género suele basar parte de «su existencia virtual (...) en los imaginarios prehispánicos», ${ }^{15}$ como las pirámides aztecas que reaparecen en el diseño de las ciudades del futuro y que «las ciudades latinoamericanas contemporáneas» (2007: 67) como México, Lima —el espacio global representado en Control Terrestre - o São Paulo muchas veces sirven de decorado para resaltar las deficiencias político-sociales señaladas más arriba y formular una crítica tajante de la modernización.

\subsection{La deslegitimación de la verdad única: un posible mundo paralelo}

Aunque la amenaza de la modernización también está presente en «El archivo de N», «No mirar por las ventanas» $\mathrm{y}$ «La nave olvidada», estos cuentos más bien tienen que ver con el segundo componente distinguido por Honores, «la deslegitimación de la verdad única» (2010: 208). Basta recordar la realidad paralela inducida por la interpenetración de los acontecimientos históricos y la ficción en el primer cuento o la metalepsis que hunde al propio narrador en el segundo. Quizá este cuestionamiento de la realidad convencio-

14. A esta altura, Peregrina señala que el propio subgénero de «la ciencia-ficción ha adaptado las herramientas narrativas del posmodernismo» (2015: 1), por lo que también se observa en él un interés creciente por «las influencias y referencias literarias» (2015: 9), tales como las hemos señalado en lo fantástico de lenguaje en Güich Rodríguez.

15. Este aspecto se ilustra, por ejemplo, en los cuentos de otros dos autores peruanos, «El falsificador», de José B. Adolph, y «Quipucamayoc», de Daniel Salvo, que remodelan la tradición incaica valiéndose de la ciencia ficción. Según José Donayre (2010), el primero «falsifica» una crónica hispánica acerca de la divinidad de Viracocha, situando la narración en una nave espacial que hace suponer la existencia de una entidad todavía superior al supuesto Dios Supremo, y el segundo relaciona los «quipus», los nudos que les servían a los incas de instrumento de comunicación, con unos atributos del mundo digital contemporáneo, por lo que se llena de misterio la historia convencional. 
nal se ilustra de manera más clara en «La nave olvidada», donde la obsesión del norteamericano Floyd por la gestión del tiempo basada en la estereotipada oposición intercultural entre la eficacia estadounidense y los «rodeos» que suelen dar los «exóticos» peruanos «antes de ir al asunto» (Güich Rodríguez, 2013: 113) se ve neutralizada por los supuestos logros aeronáuticos del Perú. Efectivamente, las aventuras con la misteriosa nave espacial, les dan crédito a Díaz y a su amigo Enrique a pesar de que solo eran «dos chicos de doce años en un país del Hemisferio Sur» (2013: 117) y le invitan a aquel a avanzar que «la historia de los viajes espaciales comenzó» en el Perú, acontecimiento pionero que dicho «sin ningún chauvinismo (...) [h]asta Von Braun reconoció» (2013: 123). Atacándose a unos arquetipos interculturales e invirtiendo las relaciones de fuerzas entre el Perú y los Estados Unidos, la vacilación engancha con una temática poscolonial más amplia y permite que Díaz le recomiende a Floyd «que no utilice la palabra "imposible" con tanta frecuencia» (2013: 124) y fuerce así una apertura mental para creer en la existencia de otras realidades posibles.

También encaja en esta categoría «Nocturno de Viena» que elabora un retrato históricamente bastante dudoso de Wolfgang Amadeus Mozart. Este no aparece tanto en su calidad de músico genial sino como personaje extravagante que en las noches de luna llena va recogiendo en «el descampado entre las murallas y los suburbios» de Viena unos «restos de metal que dejan los soldados luego de sus maniobras» (2013: 52). Es allí, en las orillas del Danubio, donde el compositor también percibe una incomparable «música que brotaba de la nada (...) como si todos los principios conocidos sobre armonía se descoyuntaran» y «hasta se distinguen aplausos y rumores de voces» (2013: 53). Esta imagen es la que Mozart hace de sí mismo en una carta al protagonista, cuya identidad no se desvela —excepción hecha de unas borrosas alusiones a la amistad con Ludwig Von Beethoven y a «las notas del himno que compuso para Austria» (2013: 59)— hasta en el último párrafo del cuento: su antiguo maestro «Franz Joseph Haydn» (2013: 63). La lectura de la carta estimula a Haydn, un «viejo baldado rumbo al cementerio» (2013: 48) y aterrado por los cañonazos de los ejércitos napoleónicos que asedian la ciudad, a desplazarse al espacio que le describió su discípulo muerto ya. En esos parajes oye cómo le llegan desde una fuente desconocida los mismos aplausos y una música que parece sintetizar la suya y la de sus amigos Ludwig y Wolfgang. También ve cómo sus nombres se mezclan con los de unos artistas posteriores a ellos «Schoenberg, Webern y Berg» en el anuncio de un concierto programado en «un año inverosímil que no es ni 
por asomo el que corre, es decir, 1809» (2013: 62). Estas singulares experiencias «parecen ser el puente, el vínculo lógico entre un presente y un futuro que está por hacerse del cual [el héroe] presencia unos cuantos retazos» y terminan sugiriendo la existencia de un mundo paralelo. Este paralelismo también se observa en el espacio del cuento que se convierte en una «Viena que nunca duerme» (2013: 63) y parece revestir el aspecto que muchos años más tarde tendrá Nueva York.

Una misma confusión de universos se establece en «El Sembrador», relato en el que el narrador Alberto Teruel — posible pariente del héroe de «El archivo de $\mathrm{N}$ »- es intrigado por un profesor «cuya presencia era a todas luces inquietante» (2013: 42). Este considera la guerra del Pacífico que se desarrolla por aquellas fechas como una «catástrofe [que] no era nada comparada con las que el mundo contemplaría en relativamente poco tiempo» (2013: 39) y se pasea sigilosamente por el centro de Lima. Allí lleva a cabo «alguna especie de medición» y enfoca unos edificios históricos por medio de un especial «objeto rectangular, transparente, con luces, números y líneas que cambiaban de forma» que solo más tarde resulta ser una "cámara» (2013: 42, 46). Ya de viejo, Teruel se encuentra otra vez con su exprofesor y, al notarlo igual que antes, entiende que no le afectan las leyes del tiempo y pertenece a otro mundo. Además, la afinidad que este personaje parece tener con un enigmático «Sembrador y sus colegas» (2013: 46) invita a interpretar las singulares mediciones que efectuó hace muchos años y sus extrañas teorías «sobre la colonización de todo el sistema solar en unos doscientos cincuenta años, de los recursos escasos en el planeta, de la necesidad de buscar nuevas fuentes de alimento para la especie» (2013: 43) como un discurso ecologista anticipado. De este modo, estas reflexiones constituirían un tipo de «semillas» para hacer brotar una realidad nueva, más refinada que la que vive el protagonista, quien «aún pertenece a un mundo cuya infancia apenas profiere sus primeros balbuceos, o se asoma a la entrada de la caverna» (2013: 46).

Finalmente, el cuestionamiento de la realidad se lleva a cabo en su dimensión propiamente política en «El visitante», relato en el que un tal Coppelius, por medio de un misterioso «cinturón» que emite «una radiación calórica» (2013: 97), sabe forzarse imperceptiblemente una entrada a un centro penitenciario fortificado, orgullo del gobierno peruano. Allí se hace justicia por sí mismo, sacándoles los ojos a los delincuentes de la peor calaña de manera sumamente diestra: estos solo se dan cuenta de la extirpación al despertarse y las cavidades se les cicatrizan en el acto. Mediante una astucia, Gándara —un antiguo policía que ya aparece en «Paisaje con hombre que corre», 
otro cuento de Güich ${ }^{16}$ - consigue desenmascarar al extraño personaje y se entera de que este revive un antiguo mito alemán, «una historia aterradora sobre un personaje que se llevaba los ojos de los niños reacios a dormir para devorarlos luego» ${ }^{17}$ (2013: 96) para aplicárselo a «los peores criminales»y, más específicamente, a los peruanos, cuyos ojos «son el manjar más delicioso que existe» (2013: 97). Sin embargo, Coppelius logra escaparse del interrogatorio, le come los ojos al corrupto asesor Monteblanco, quien había intentado silenciar el caso para no desprestigiar al régimen, y desencadena así «una crisis política sin proporciones» (2013: 98):

Las fuerzas de la oposición utilizaron el episodio como eficaz arma para reclamar el retorno a la democracia y no prolongar esa farsa en que se había convertido el gobierno. (...) Fukuyama estaba al borde del colapso (...) estaba deshecho ante la pérdida de quien había movido los hilos del poder durante diez años, protegiéndole las espaldas de todos sus enemigos. (...) Ya no había arrogancia ni desprecio por los otros; solo un guiñapo humano (Güich Rodríguez, 2013: 98-99).

Huelga decir que los parónimos «Fukuyama»y «Monteblanco» son unas claras referencias al expresidente peruano Alberto Fujimori y a su consejero y antiguo Jefe del Servicio de Inteligencia, Vladimiro Montesinos, acusados de corrupción y de terrorismo de estado. ${ }^{18}$ Además, el fragmento tematiza el «autogolpe» o «Fujigolpe» que dio aquel en el 1992 al disolver el Congreso con la ayuda de los militares y, más adelante, se alude a su huida al Japón, lugar en el que quería estar a salvo de la justicia y donde, en el 2000, abandonó finalmente su cargo presidencial. Como lo señala Honores, por este camino el cuento termina constituyendo «una ucronía de la dictadura fujimorista» (2012b: 465): cuando Gándara nota que Coppelius no da señales de enmienda, le suministra las direcciones necesarias para que este pueda ajusticiar con efecto retroactivo al expresidente Fukuyama, «un criminal de talla mayor» que vive exiliado en Japón y que para él «[s]erá un banquete» (2013: 100). De

16. Este relato está integrado en la colección El mascarón de proa (2006) y su aspecto fantástico consiste en el hecho de que un hombre se esfuma misteriosamente en los años 30 para reaparecer atropellado, con una edad inalterada, en la Lima de los 90.

17. A estas alturas, lo fantástico reanuda con la intertextualidad: como lo señala Honores, el «asesino imposible llamado Coppelius» remite al «personaje diabólico de "El hombre de arena" de Hoffman» (2012a: 465).

18. El fujimorismo también es tematizado en otras novelas peruanas como, por ejemplo, Cinco esquinas (2016), de Mario Vargas Llosa, o Gris: las vidas de las penumbras (2004), de Carlos Herrera. Su elaboración en el citado cuento de Güich muestra hasta qué punto la ciencia ficción o lo fantástico pueden convertirse en una herramienta literaria para evocar unas realidades políticas. 
esta manera, los diferentes aspectos fantásticos mencionados les ofrecen unas alternativas a los hechos reales y permiten que se lea el cuento como un desquite con la historia oficial.

\section{Conclusiones}

En resumen, en la colección de cuentos Control Terrestre de Güich Rodríguez se materializa una concomitancia entre un fantástico de percepción y un fantástico de lenguaje. Más específicamente, la vacilación que es responsable del efecto fantástico arraiga en la tematización de unos objetos de alta tecnología como cápsulas, cohetes o submarinos, y en unos experimentos con la enunciación que son constitutivos del género en la época postmoderna. Este fantástico de lenguaje toma cuerpo en una narración que combina unos artificios narrativos como la metalepsis o la dilatación del tiempo con la insistencia en la propia literatura. A este respecto, la metaficción muestra cómo la narración es contrarrestada por su propio objeto, lo que fortalece la sensación de lo insólito. La intertextualidad, por su parte, contribuye a lo fantástico de manera explícita, invocando unos textos que hacen época en el género, o implícita, entablando conjetural y subrepticiamente un diálogo con un texto cuyo aspecto aparentemente realista intensifica la duda.

La compenetración de ambos procedimientos se hace todavía más visible en el hecho de que estos terminan articulando en todos los relatos concernidos un discurso subversivo y, por lo mismo, contrarrestan una tendencia bastante generalizada en la crítica literaria a tachar la literatura fantástica de «escapista». Tanto lo fantástico de percepción como lo fantástico de lenguaje permiten formular una crítica de la modernización y motivan una deslegitimación de la verdad única. Estas ideas finalmente se concretan reproduciendo un mundo contemporáneo deshumanizado, a través de unas imágenes distópicas y la burla de la grandilocuencia, o barajando la hipótesis de que exista algún universo paralelo al mundo convencional, unas representaciones que todas dejan claras las implicaciones ideológicas que puede llegar a tener lo fantástico.

\section{BIBLIOGRAFÍA}

Bensoussan, Albert (1985): «Alfredo Bryce Echenique, le principe d'innocence», Co-textes, núm. 9 , pp. 45-53. 
Bianco Amaral, Ana Carolina (2012): «Notas sobre a intertextualidade no gênero fantástico», Revista Rascunhos Culturais, núm. 3:6, pp. 49-62.

$<$ https:/ / doi.org/10.17851/2317-4242.3.0.276-291>

Brown, Andrew J. (2007): «Tecno-escritura: literatura y tecnología en América Latina», Revista Iberoamericana, vol. LXXIII, núm. 221, pp. 735-741. <https://doi. org/10.5195/reviberoamer.2007.5315>

Bryce Echenique, Alfredo (1981): Cuentos completos, Alianza, Madrid.

Chanady, Amaryll Béatrice (1985): Magical Realism and the Fantastic. Resolved versus Unresolved Antinomy, Garland Publishing, NuevaYork/Londres.

DONAYre, José (2010): «La cultura inca en dos cuentos de ciencia ficción: "El falsificador" de José B. Adolph y "Quipucamayoc" de Daniel Salvo», en Ciencia Ficción Perú, disponible en http://cifiperu.blogspot.be/2010/10/la-cultura-inca-endos-cuentos-de.html [fecha de consulta: 08/06/2016].

ERdal Jordan, Mery (1998): La narrativa fantástica. Evolución del género y su relación con las concepciones del lenguaje, Vervuert/Iberoamericana, Frankfurt/ Madrid.

Genette, Gérard (1972): Figures III, Seuil, Paris.

Gignoux, Anne-Claire (2006): «De l'intertextualité à l'écriture», Cahiers de Narratologie [En ligne], núm. 13, <http://narratologie.revues.org/329>. <https://doi. org/10.4000/narratologie.329>

Güich Rodríguez, José (2013): Control Terrestre, Ediciones Altazor, Lima.

Honores, Elton (2010): Mundos imposibles. Lo fantástico en la narrativa peruana, Cuerpo de la metáfora, Lima.

(2011): Lo fantástico en Hispanoamérica, Cuerpo de la metáfora, Lima.

(2012a): "Monstruos de papel: la "nueva ola" del horror peruano", Revista Letras E Letras, núm. 28, pp. 457-468.

(2012b): Narrativas del caos, Cuerpo de la metáfora, Lima.

Kurlat Ares, Silvia (2012): «La ciencia-ficción en América Latina: entre la mitología experimental y lo que vendrá», Revista Iberoamericana, vol. LXXVIII, núm. 238239, pp. 15-22. <https:/ / doi.org/10.5195/reviberoamer.2012.6884>

MACEdo Rodríguez, Alfonso (2010): «La metaficción y la intertextualidad: Figuras de lo fantástico en La Ciudad Ausente», Signos Literarios, pp. 57-75.

Martín BARbero, Jesús (2002): Oficio de cartógrafo. Travesías latinoamericanas de la comunicación en la cultura, FCE, México.

McHale, Brian (1987): Postmodernist Fiction, Methuen, Nueva York/Londres.

Musset, Alain (2007): «Entre la ciencia ficción y las ciencias sociales : el "lado oscuro" de las ciudades americanas», Revista eure, vol. XXXIII, núm. 99, pp. 65-78. <https:/ / doi.org/10.4067/s0250-71612007000200006>

Peregrina, Mikel (2015): «La ciencia ficción y la narrativa posmoderna: hacia la convergencia», Alambique: Revista académica de ciencia ficción y fantasía / Jornal acadêmico de ficção científica efantasia, vol.3:1,pp.1-20. <https:/ / doi.org/10.5038/21676577.3.1.2>

RoAs, David (2011): «Más allá de los límites del lenguaje. Lo fantástico como subversión discursiva», en Elton Honores (ed.), Lo fantástico en Hispanoamérica, Cuerpo de la metáfora, Lima, pp. 263-272. 
(2012): «Cronologías alteradas. La perversión fantástica del tiempo», en Flávio Garcia; Maria Cristina Batalha (eds.), Vertentes teóricas y ficcionais do Insólito, Editora Caetés, Rio de Janeiro, pp. 106-113.

Rodríguez Hernández, Tahiche (2010): «La conspiración fantástica: una aproximación lingüístico-cognitiva a la evolución del género», Espéculo. Revista de estudios literarios, núm. 43, pp. 1-11. http://www.ucm.es/info/especulo/numero43consfan.html.

Rubio, Cecilia (2012): «Las im(posibilidades) de lo fantástico y de la 'inquietante extrañeza' en la narrativa vanguardista de Felisberto Hernández y de Juan Emar», Acta Literaria, núm. 44, pp. 89-103. <https:/ / doi.org/10.4067/s0717-684820120 00100006>

SNAUWAERT, Erwin (2016): «La metaficción y la intertextualidad como catalizadores de lo fantástico en tres cuentos de Control Terrestre de José Güich Rodríguez», Revista Olho d'água, núm. 8:2, pp. 141-159.

http://www.olhodagua.ibilce.unesp.br/index.php/Olhodagua/article / viewFile/352/332

Todorov, Tzvetan (1970): Introduction à la littérature fantastique, Seuil, París.

Zavala, Lauro (1998): Cuentos sobre el cuento. Teorías del cuento, Universidad Nacional Autónoma de México, Ciudad de México. 